\title{
Research on Influencing Factors of Effective Gas Extraction Radius in Coal Mine Based on Multiple Linear Regression
}

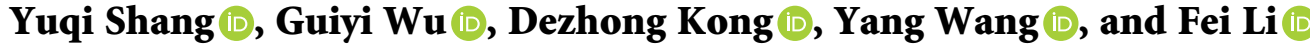 \\ College of Mining, Guizhou University, Guiyang 550025, Guizhou, China \\ Correspondence should be addressed to Guiyi Wu; gywu@gzu.edu.cn and Dezhong Kong; dzkong@gzu.edu.cn
}

Received 12 November 2021; Revised 10 December 2021; Accepted 22 December 2021; Published 28 January 2022

Academic Editor: Veronica Calado

Copyright ( $\odot 2022$ Yuqi Shang et al. This is an open access article distributed under the Creative Commons Attribution License, which permits unrestricted use, distribution, and reproduction in any medium, provided the original work is properly cited.

\begin{abstract}
In order to analyze the influence degree of different factors on gas extraction radius, on the basis of coal seam gas flow theory and elastic mechanics, considering the influence of coal seepage rate change on gas flow, the COMSOL Multiphysics numerical simulation software is secondarily developed by using the stress-seepage coupling mathematical model of coal and rock containing gas. Taking coal seam No.2 of Juji Coal Mine as an example, the effective extraction radius under different extraction negative pressure, extraction borehole diameter, extraction time, and initial permeability of coal seam are simulated, respectively. Then, the orthogonal test method is used to design different calculation schemes, and the effective extraction radius is used as the judgment index. The simulation software is used to calculate the effective extraction radius corresponding to different influencing factors. SPSS statistical software is used to analyze the parameters. The multivariate linear regression equation of the influencing factors of the effective extraction radius is obtained, and the multivariate linear regression model is established. The results show that the negative pressure of extraction has little effect on the effective extraction radius; the effective extraction radius gradually expands with the increase of extraction time and extraction aperture, but it has certain timeliness. The initial permeability of the coal seam has a great influence on the effective extraction radius. The influence degree of different influencing factors from large to small is the initial permeability of coal seam, extraction time, borehole diameter, and extraction negative pressure. Therefore, the key to improving the effectiveness of gas extraction is to increase the initial permeability of the coal seam before preextraction, ensure sufficient extraction time, appropriately increase the borehole diameter, and improve the negative pressure of extraction. Finally, the gas flow rate is used for a field test, and the measured results are basically consistent with the simulation results, which proves the correctness of the mathematical model of gas-containing coal and the feasibility of using numerical simulation methods to study the effective extraction radius of coal seams.
\end{abstract}

\section{Introduction}

For outburst mines, preextraction of coal seam gas is a very important outburst prevention measure. In the design of gas extraction, effective extraction radius is an important parameter of the measure, which is directly related to the design of preextraction borehole spacing and affects the effect of gas extraction. If the distance between the gas extraction holes is too small, the construction volume of the gas extraction holes will inevitably increase; if the distance between the gas extraction holes is too large, it will leave a blank area for gas extraction, increase the gas extraction time, and affect the extraction effect and recovery speed. The poor effect of gas extraction may lead to the occurrence of gas disasters.

Gas migration in a coal seam is a very complex gas-solid coupling dynamic problem. In the process of mining, with the decrease of pore pressure, the effective stress of coal increases, which will inevitably lead to changes in porosity, permeability, and other parameters of coal. At present, the research on gas extraction radius mostly adopts numerical simulation, which is more accurate and saves manpower and material resources than the field test method. However, most of these studies focus on gas pressure, gas extraction volume, and hole layout, and there are few studies on the influencing factors of effective extraction radius. Therefore, in the study 
of the influencing factors of effective gas extraction radius by using numerical simulation software, the establishment of a gas-solid coupling model and its accuracy are particularly important $[1,2]$.

In recent years, many domestic and foreign experts and scholars have conducted a lot of research on the gas-solid coupling model of gas-bearing coal and the factors affecting the effective extraction radius and have achieved rich results. Liang et al. established a coupled seepage model for gas extraction based on the comprehensive consideration of the deformation characteristics of coal rock skeleton and the adsorption and desorption characteristics of gas in coal porous media [3]. Zhao et al. derived the gas seepage equation according to the mass conservation equation and ideal gas state equation. Darcy's law simulated the change of coal seam gas content with time and analyzed the relationship between gas flow and time [4]. Liu et al. established a physical field fluid-solid coupling model considering the Klinkenberg effect, effective stress, and absorption shrinkage and studied the evolution law of permeability and porosity around the borehole [5]. Hao et al. established a fluid-solid coupling model considering the creep effect of coal and determined the effective extraction radius of boreholes with different depths [6]. Yin et al. established the compressible gas-solid coupling model of skeleton deformable gas and simulated the gas extraction under excavation [7]. Wang et al. established a dynamic change model of coal seam permeability considering effective stress change, gas desorption, and coal matrix shrinkage effect [8]. Cheng et al. established a physical model considering diffusion movement and Darcy flow and studied the change of gas pressure at the measuring points of two borehole centers [9]. Liu et al. simulated the distribution of gas pressure under different adsorption times and the influence of the Klinkenberg effect on gas extraction [10]. Guo et al. obtained the influence of negative pressure, extraction time, and borehole radius on effective extraction radius by using numerical simulation method and proposed the concept of pressure difference improvement ratio to compare and analyze the negative pressure and gas pressure [11]. Wang et al. measured the gas pressure, gas content, drilling cuttings gas desorption index, and gas flow rate in the bedding boreholes on-site, using a combination of direct and indirect measurement methods to determine the effective drainage radius of the bedding borehole [12]. According to Cheng et al., based on the gassolid coupling model of gas extraction by borehole along the seam, the influencing factors of effective radius are analyzed from two aspects of coal seam occurrence parameters and extraction parameters [13].

In this paper, based on the comprehensive consideration of coal skeleton deformation, coal pore pressure, and adsorption expansion force during gas extraction, the stressseepage gas-solid coupling model during gas extraction is used, and the drilling model is established in the numerical software COMSOL Multiphysics to simulate the gas extraction of coal seam No.2 in Juji Coal Mine. The effects of negative pressure, extraction aperture, extraction time, and initial permeability of coal on the effective extraction radius are studied. Then, the orthogonal test analysis was carried out on multiple factors affecting the effective gas extraction radius, and the effective gas extraction radius was used as the judgment index to obtain the influence degree of each factor. Finally, the multivariate linear regression analysis of each factor was carried out by using the statistical analysis software SPSS, and the regression equation of each factor was obtained. The multivariate linear regression equation of the effective gas extraction radius was established. The effective gas extraction radius of the borehole was measured by using the gas flow method in the mining area of the lower drainage roadway of Juji Coal Mine 2616 so as to verify the correctness of the coupling model of coal rock containing gas and the feasibility of using COMSOL software to simulate the effective gas extraction radius of coal seam drilling.

\section{Establishment of Gas-Solid Coupling Mathematical Model of Gas Flow}

2.1. Gas Seepage Field Equation. Because the gas flow in porous media conforms to the law of mass conservation of gas phase [14], the mass difference between inflow and outflow of the control volume is equal to the mass change of control volume in unit time. The continuity equation of gas flow is as follows:

$$
\frac{\partial Q}{\partial t}+\nabla(\rho V)=0
$$

In the formula: $Q$ is the gas mass per unit volume of gascontaining coal, $\mathrm{kg} / \mathrm{m}^{3} ; t$ is time, $\mathrm{s} ; \rho$ is coal seam gas density, $\mathrm{kg} / \mathrm{m}^{3} ; \mathrm{V}$ is gas seepage velocity, $\mathrm{m} / \mathrm{s}$.

Gas in coal seam exists in a free state and adsorption state. The free gas conforms to the ideal gas state equation, and the adsorbed gas satisfies the Langmuir isothermal adsorption equation. According to the coal seam gas content equation and effective stress equation, coal seam gas flow equation can be obtained:

$\beta\left(p \frac{\partial \varphi}{\partial t}+\varphi \frac{\partial p}{\partial t}\right)+\beta \frac{a b c p_{n}}{(1+b p)^{2}} \frac{\partial p}{\partial t}+\nabla\left[\frac{k}{2 \mu}\left(1+\frac{m}{p}\right) \nabla p^{2}\right]=0$.

In the formula: $\beta$ is the compressibility factor of coal seam gas, $\mathrm{kg} /\left(\mathrm{m}^{3} \cdot \mathrm{Pa}\right) ; p$ is gas pressure, $\mathrm{Pa} ; \varphi$ is coal porosity; $a$ is the limit adsorption capacity per unit mass of coal, $\mathrm{m}^{3} /$ $\mathrm{kg}$; $\mathrm{b}$ is coal. The adsorption constant, $\mathrm{MPa}^{-1} ; \mathrm{c}$ is the mass of combustibles per unit volume of coal, $\mathrm{kg} / \mathrm{m}^{3} ; p_{\mathrm{n}}$ is the gas pressure under standard conditions, $\mathrm{Pa} ; k$ is the coal permeability, $\mathrm{m}^{2}$; $\mu$ is the dynamic viscosity of the gas, $\mathrm{Pa} \cdot \mathrm{s} ; \mathrm{m}$ is the Klinkenberg coefficient, $\mathrm{Pa}$.

2.2. Gas Permeability Model. Permeability is an important index of the difficulty of gas flow in coal seam [15], and it is also an important parameter of gas drainage. Coal containing gas is a porous medium. In the process of gas extraction, the decrease of pore pressure of coal, the desorption effect of coal matrix, and the change of effective stress will affect the change of permeability. The porosity equation can be obtained by considering the influence of gas pressure, gas desorption, and volumetric strain of coal in the stress field. According to the Kozeny-Carman equation, the relationship 
between porosity and permeability can be obtained, and then the coal permeability equation can be obtained:

$$
k=\frac{k_{0}}{1+\varepsilon_{\mathrm{v}}}\left[1+\frac{\varepsilon_{\mathrm{v}}}{\varphi_{0}}+\frac{\left(1-\varphi_{0}\right) \triangle p}{\varphi_{0} k_{\mathrm{s}}}+\frac{2 a \rho_{\mathrm{s}} \mathrm{RT}}{9 k_{\mathrm{s}} \mathrm{V}_{\mathrm{m}} \varphi_{0}} \ln \frac{1+b p_{0}}{1+b p}\right]^{3} .
$$

In the formula: $k_{0}$ is initial permeability of coal, $\mathrm{m}^{2} ; \varepsilon_{\mathrm{v}}$ is the volumetric strain of coal mass; $\varphi_{0}$ is the initial porosity of coal; $\Delta p$ is the change of gas pressure, $\mathrm{Pa} ; k_{\mathrm{s}}$ is the bulk modulus of coal, $\mathrm{Pa}$; $\rho_{s}$ is the apparent density of coal, $\mathrm{kg} / \mathrm{m}^{3}$; $R$ is a Prussian gas constant, $\mathrm{J} /(\mathrm{kg} \cdot \mathrm{K}) ; T$ is the coal temperature, $\mathrm{K} ; V_{\mathrm{m}}$ is gas molar volume, $\mathrm{m}^{3} / \mathrm{mol} ; p_{0}$ is the initial gas pressure, $\mathrm{Pa}$.

2.3. Coal Deformation Control Equation. In the process of coal seam gas extraction, desorption seepage occurs when coal adsorbs gas, and the pressure in the pores decreases, resulting in deformation under the stress of overlying strata. It is generally believed that the deformation of coal is affected by the combined action of ground stress, gas pressure, and expansion stress caused by gas adsorption expansion. Based on Wu's calculation formula of coal swelling stress, Guo's expression form of coal volumetric strain tensor, effective stress balance formula of gas-bearing coal, and generalized Hooke's law in the online elastic deformation stage of coal deformation, the control equation of coal deformation can be deduced.

$$
\begin{aligned}
\mathrm{Gu}_{\mathrm{i}} & +\frac{\mathrm{G}}{1-2 \sigma} \mathrm{u}_{\mathrm{j}}+\left(\alpha+\frac{2 \mathrm{G}}{3 k_{\mathrm{s}}}\right) p^{\prime} \\
& -\left\{\left[\frac{4 \mathrm{G}}{9 \mathrm{~V}_{\mathrm{m}} k_{\mathrm{s}}}-\frac{2(1-2 \sigma)}{3 \mathrm{~V}_{\mathrm{m}}}\right] \frac{a b \rho_{\mathrm{s}} \mathrm{RT}}{1+b p}\right\} p^{\prime}+\mathrm{F}=0 .
\end{aligned}
$$

In the formula: $G$ is the shear modulus, GPa; $u_{i}$ and $u_{j}$ are displacement components in horizontal and vertical directions, $\mathrm{m}$; $v$ is the Poisson's ratio of gas-containing coal rock; $\alpha$ is Biot coefficient; $p^{\prime}$ is gas pressure component, $\mathrm{Pa} ; \mathrm{F}$ is body stress, $\mathrm{N} / \mathrm{m}^{3}$.

Equations (3) and (4) together constitute the stressseepage coupling model of gas-bearing coal rock.

\section{Simulation Study on Variation Law of Effective Extraction Radius}

Among all the parameters related to boreholes [14-16], the controllable factors include extraction time, borehole diameter, and extraction negative pressure. At the same time, the initial permeability of coal seam can be changed by pressure relief and permeability enhancement measures. These controllable factors will affect the size of the effective extraction radius. In this section, with the help of the gassolid coupling mathematical model of gas flow established above, the multiphysical field coupling simulation software COMSOL Multiphysics is secondarily developed to simulate the influence of various controllable factors on the effective extraction radius, determine the change rule of effective extraction radius, and put forward the corresponding explanation, in order to provide a reference for the selection of field drilling construction scheme [16-18].
Based on the relevant physical and mechanical parameters of coal seam No.2 in Juji Coal Mine (the parameters needed for calculation are shown in Table 1), a numerical model with length $\times$ width $=40 m \times 2 \mathrm{~m}$ is established, and the borehole is simplified to circles with different diameters, as shown in Figure 1.

According to the Interim Provisions of Coal Mine Gas Extraction standard, $0.74 \mathrm{MPa}$ can be used to determine whether the coal seam gas pressure is up to standard. In addition, it is pointed out in Article 190 of coal Mine Safety Regulations that after the implementation of predrainage of coal seam gas, the prominent prevention, and control effect of predrainage of gas must be tested, and the gas content after extraction is less than $30 \%$ of that before extraction. Therefore, in this paper, the residual gas pressure of the coal seam is lower than $0.74 \mathrm{MPa}$ or the extraction rate of $30 \%$ is defined as the standard extraction area, and the radius of this area is called the effective extraction radius.

The initial condition of the model is set: when $T=0$, the original gas pressure of the coal seam is $1.41 \mathrm{MPa}$. Boundary conditions: coal seam boundary is set to the second kind of boundary conditions, namely the gas flux of the coal boundary is 0 ; the borehole boundary is set to the first boundary condition, which is the extraction negative pressure.

3.1. Influence of Negative Pressure on Effective Gas Extraction Radius. In order to study the variation of gas drainage radius of gas drainage borehole under different negative pressure conditions, the borehole diameter is $94 \mathrm{~mm}$, the initial permeability is $4.4 \times 10^{-17} \mathrm{~m}^{2}$, and the extraction negative pressure of the hole borehole is set to be $8 \mathrm{kPa}$, $13 \mathrm{kPa}, 18 \mathrm{kPa}, 23 \mathrm{kPa}, 27 \mathrm{kPa}$, and $30 \mathrm{kPa}$. The variation of the pressure relief range of the gas pressure and the effective gas extraction radius of different extraction negative pressures at the same time are analyzed with the increase of the extraction negative pressure.

It can be seen from Figure 2 that with the increase of extraction negative pressure, the range of gas pressure relief increases, but the increase is small. When the gas extraction time is 60 days, the distribution of gas pressure is shown in Figure 3. When the gas pressure is greater than $0.2 \mathrm{MPa}$ and $0.1 \mathrm{MPa}$, respectively, the gas pressure distribution curve changes little with the extraction negative pressure, and there are only near $1 \mathrm{~m}$ from the borehole center.

The variation of effective extraction radius with time under different extraction negative pressures is shown in Figure 4, and each curve is almost coincident, indicating that under different extraction negative pressures, after the same extraction time, the effective extraction radius has almost no change. The borehole gas drainage mainly uses the pressure difference between the gas pressure in the coal body and the negative pressure in the borehole so as to drive the gas in the coal seam to flow into the borehole. The variation range of the negative pressure is very small compared with the gas pressure in the coal seam itself. Therefore, the pressure difference between the negative pressure in the borehole and the gas pressure in the coal seam is maintained at a relatively 
TABle 1: Physical parameters of the model.

\begin{tabular}{lcc}
\hline Parameter & Numerical value & Parameter units \\
\hline Density of coal, $\rho_{\mathrm{s}}$ & $1.47 \times 10^{3}$ & $\mathrm{Kg} \cdot \mathrm{m}^{-3}$ \\
Initial porosity of coal, $\varphi_{0}$ & 5.06 & $\mathrm{MPa}$ \\
Initial gas pressure of coal, $P_{0}$ & 1.4 & $\mathrm{~K}$ \\
Temperature, T & 293.14 & - \\
Poisson's ratio of coal, $v$ & 0.37 & $1.21 \times 10^{5}$ \\
Gas dynamic viscosity, $\mu$ & 28.327 & $\mathrm{~Pa}^{-\mathrm{s}}$ \\
Maximum adsorption capacity per unit mass of coal, a & 0.793 & $\mathrm{~m}^{3} \cdot \mathrm{kg}^{-1}$ \\
Adsorption constant, b & $\mathrm{MPa}^{-1}$ \\
\hline
\end{tabular}

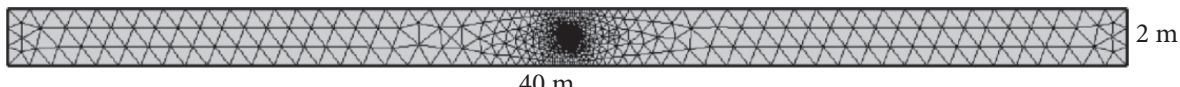

$40 \mathrm{~m}$

Figure 1: Geometric model.

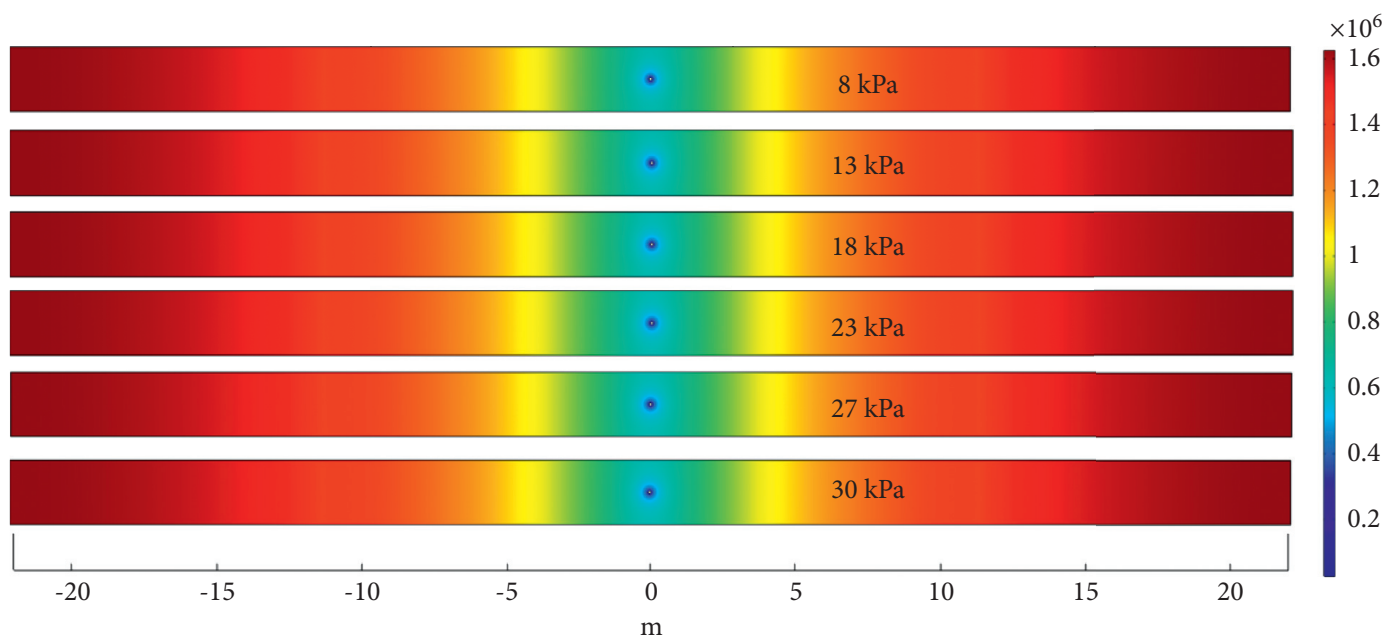

FIGURE 2: Cloud diagram of the influence range of different extraction negative pressure changes.

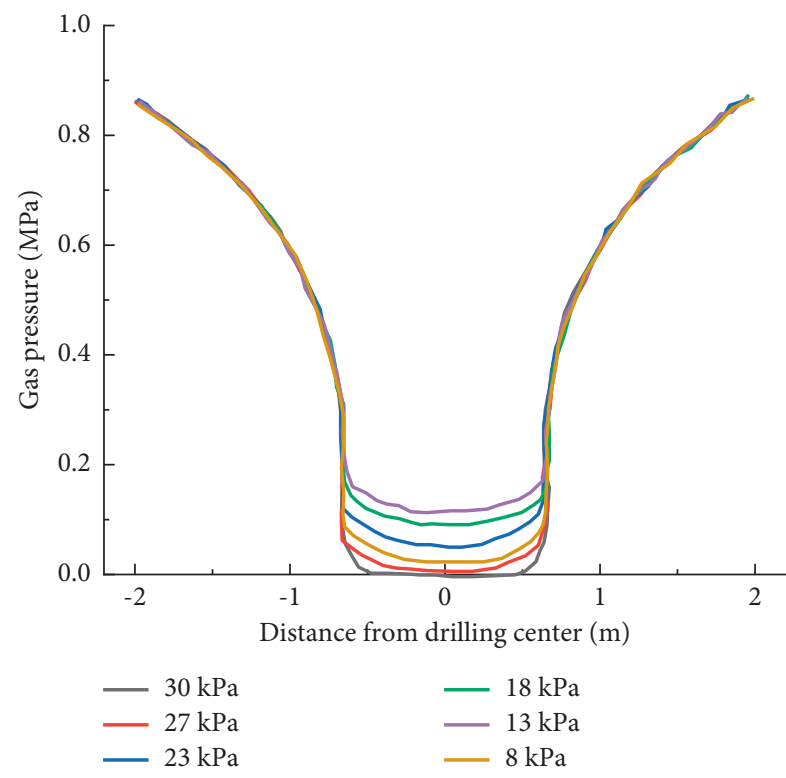

FIGURE 3: Change of gas pressure with extraction negative pressure after $60 \mathrm{~d}$ of drainage.

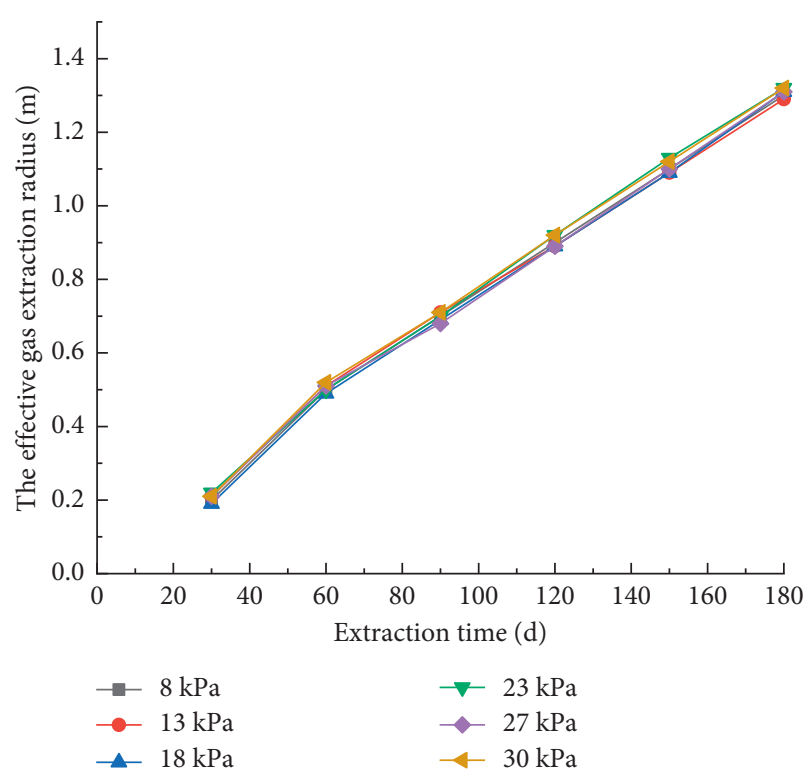

FIgUre 4: The variation of effective gas extraction radius with time under different extraction negative pressures. 
stable level. In summary, the change of extraction negative pressure has little effect on the effective extraction radius of the borehole.

\subsection{Influence of Borehole Diameter on Effective Gas Extraction} Radius. In order to study the effect of different borehole diameters on the effective extraction radius [19-22], the extraction negative pressure was set to be $18 \mathrm{kPa}$, and the initial permeability was $4.4 \times 10^{-17} \mathrm{~m}^{2}$. The borehole diameters were selected as $75 \mathrm{~mm}, 94 \mathrm{~mm}, 113 \mathrm{~mm}, 130 \mathrm{~mm}$, $150 \mathrm{~mm}, 300 \mathrm{~mm}$, and $600 \mathrm{~mm}$, respectively.

It can be seen from Figure 5 that when the borehole diameter is $75 \mathrm{~mm}-150 \mathrm{~mm}$, as the borehole diameter increases, the slope of the relationship between the effective drainage radius and the drainage time becomes larger. This shows that as the borehole diameter increases, the effective drainage radius increases, and the longer the drainage time, the greater the increase. For example, when the drainage time is 30 days, the effective drainage radius of the $94 \mathrm{~mm}$ borehole is $0.04 \mathrm{~m}$ larger than that of the $75 \mathrm{~mm}$ borehole. When the time is $180 \mathrm{~d}$, the difference increases to $0.08 \mathrm{~m}$. However, when the diameter of the drainage borehole is larger than $150 \mathrm{~mm}$, the increase rate of the effective drainage radius slows down significantly $[23,24]$. As can be seen from the displacement cloud diagram in Figure 6, as the borehole diameter increases, the displacement around the borehole also increases, especially when the borehole diameter reaches $300 \mathrm{~mm}, 600 \mathrm{~mm}$; the drainage hole has already occurred. Therefore, it is concluded that when the hole diameter is smaller, the effective extraction radius increases with the increase of the hole diameter, but the hole diameter is not as large as possible. As the hole diameter increases, the shape of the hole is prone to deformation, collapse, and cracking, etc., which leads to very demanding requirements for the sealing material and sealing technology of the superlarge borehole, which makes it difficult to effectively increase the effective extraction radius.

\subsection{Influence of Extraction Time on Effective Gas Extraction} Radius. In order to study the relationship between the extraction time and the effective extraction radius, the fixed extraction borehole diameter is $94 \mathrm{~mm}$, the extraction negative pressure is $18 \mathrm{kPa}$, and the initial coal seam permeability is $4.4 \times 10^{-17} \mathrm{~m}^{2}$. The simulation solution calculates the extraction time of the borehole. The relationship with the effective drainage radius of the borehole is shown in Figure 7.

Taking coal body gas pressure $0.74 \mathrm{MPa}$ as the critical gas pressure drainage standard value, its corresponding drainage range is the effective gas drainage range, and its location is the effective drainage radius. From Figure 7, the effective drainage radius at different times is shown in Table 2.

Figure 7 shows the distribution of gas pressure at different extraction times [18]. When the extraction time is constant, the farther away from the borehole center, the weaker the increasing trend of gas pressure. In the early stage of gas drainage, the gas pressure changed significantly, and the decreasing trend gradually weakened with

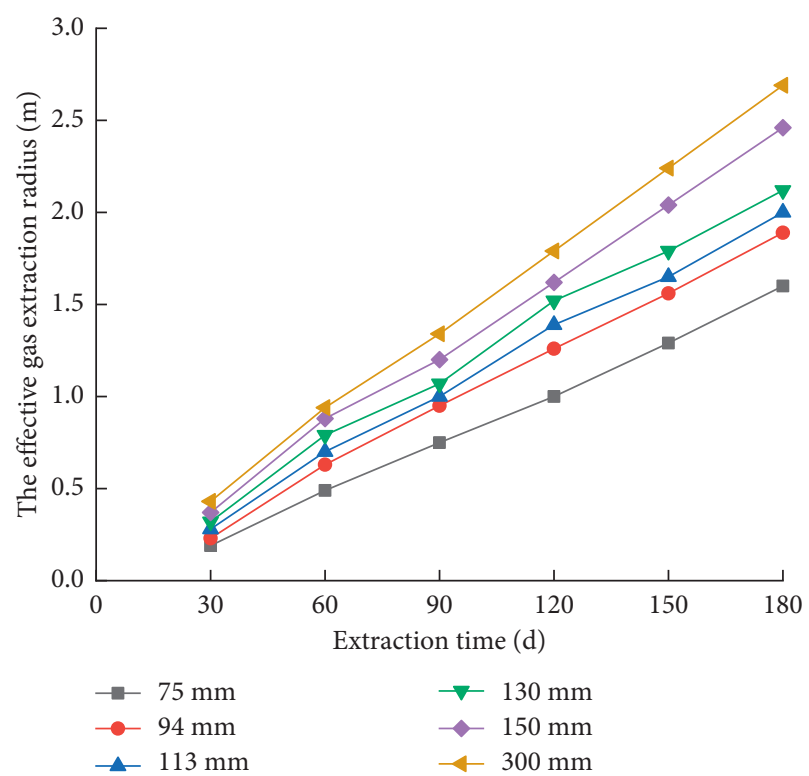

Figure 5: The variation of effective radius with extraction time under different apertures.

the increase of the drainage time. This is because the amount of gas in the borehole is relatively large at the beginning of the drainage, but with the increase of the drainage time, the permeability of the coal body continues to decrease, and the rate of decrease gradually decreases. The gas pressure in the coal seam continues to decrease, and the coal body is effectively affected. The increase in stress causes the coal body to be compressed, and the pores in the coal body gradually close, resulting in a gradual decrease in gas pressure change, and the gas drainage volume in boreholes also tends to stabilize.

3.4. Influence of Initial Permeability on Effective Gas Extraction Radius. In the process of gas extraction, the decrease of pore pressure of coal $[25,27]$, the desorption effect of coal matrix, and the change of effective stress will lead to the continuous change of coal permeability. The relationship between the two is a typical grey system, which is difficult to quantitatively study. Therefore, this paper studies the influence of initial permeability on effective drainage radius from the initial permeability of coal seam before pumping without drilling. In order to study the effect of initial permeability on the effective gas extraction radius, the negative pressure of extraction was set to $18 \mathrm{kPa}$ and the aperture was set to $94 \mathrm{~mm}$. The initial permeability of different coal seams was set to $2.4 \times 10^{-17} \mathrm{~m}^{2}, 4.4 \times 10^{-17} \mathrm{~m}^{2}, 6.4 \times 10^{-17} \mathrm{~m}^{2}$, $8.4 \times 10^{-17} \mathrm{~m}^{2}$, and $1.04 \times 10^{-16} \mathrm{~m}^{2}$, respectively. The variation law of effective extraction radius of borehole gas extraction under different initial permeability of coal seams was studied. The variation of effective gas extraction radius with time under different initial permeability conditions is shown in Figure 8.

The effective extraction radius of the five initial coal seam permeability conditions in Figure 8 is compared. The effective extraction radius of the extraction time of 


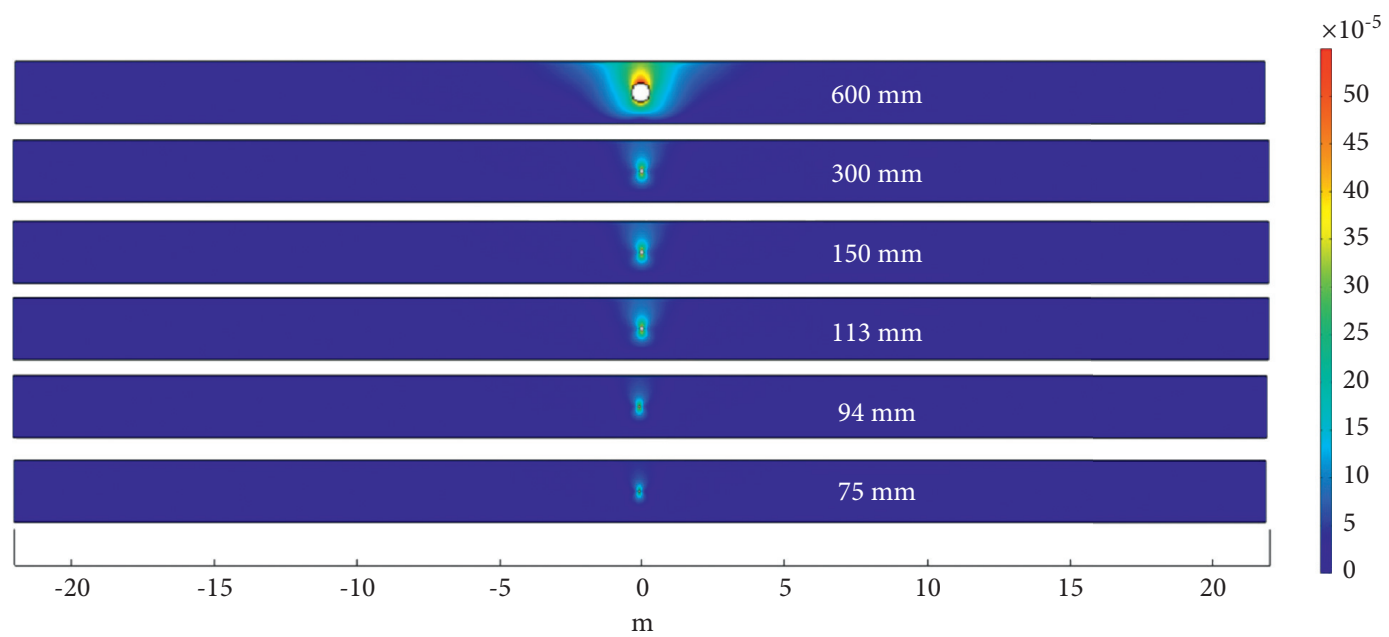

Figure 6: Displacement cloud of different hole sizes.

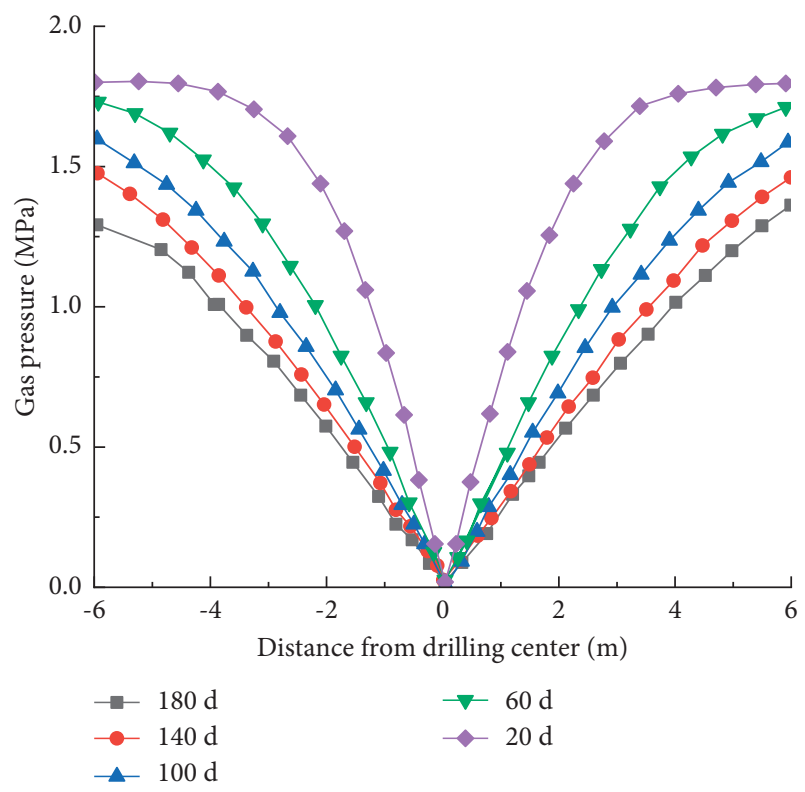

Figure 7: Gas pressure distribution curve around borehole.

TABle 2: Effective extraction radius of different extraction time.

\begin{tabular}{llllll}
\hline Extraction time (d) & 20 & 60 & 100 & 140 & 180
\end{tabular}

\begin{tabular}{llllll} 
Effective gas extraction radius $(\mathrm{m})$ & 1.24 & 1.67 & 2.09 & 2.48 & 2.97 \\
\hline
\end{tabular}

$20,60,100,140,180 \mathrm{~d}$ is $0.21 \sim 1.05,0.4 \sim 0.88,0.43 \sim 1.38,0.54$ $\sim 1.81,0.62 \sim 2.2 \mathrm{~m}$, respectively. It can be concluded that the effective extraction radius of borehole gas extraction increases with the increase of the initial permeability of the coal seam. The increase of extraction radius with the increase of permeability will increase with the extension of extraction time, so the initial permeability of the coal seam has a great influence on the effective extraction radius. The effect of increasing the initial permeability of coal seam to improve the effective extraction radius is relatively obvious.

In summary, it can be concluded that the extraction negative pressure has little effect on the effective gas extraction radius; when the hole diameter is small, the

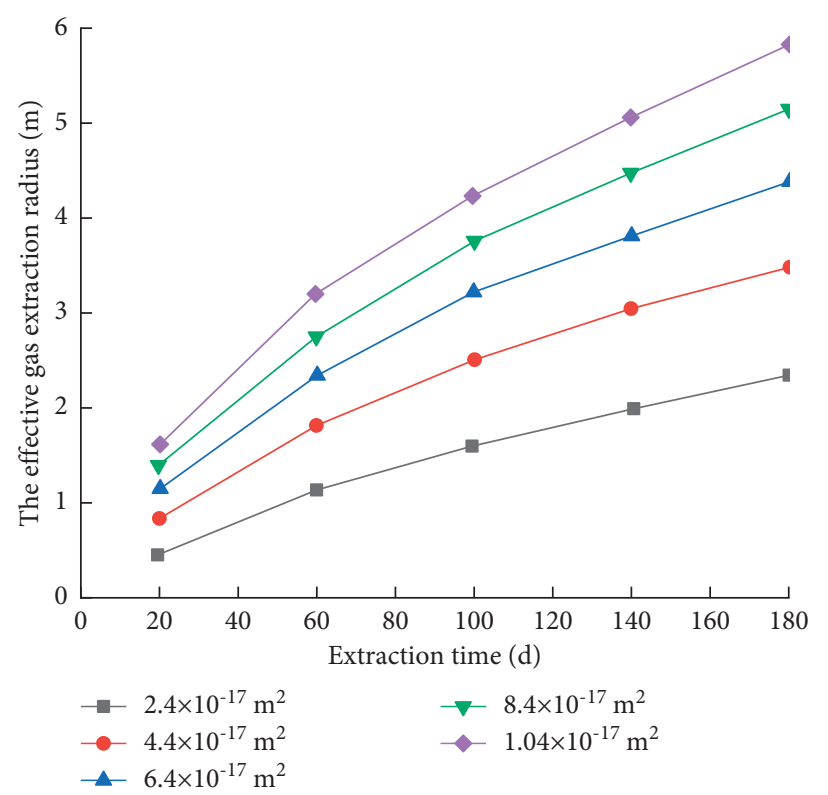

FIGURE 8: Variation of effective drainage radius with time under different initial permeability.

effective extraction radius increases with the increase of the hole diameter, but the hole diameter is not the larger the better $[28,29]$. When the hole is too large, the effective extraction radius changes little, and the displacement around the hole increases significantly. Under ideal conditions, the longer the extraction time, the larger the effective extraction radius; the effective extraction radius increases with the increase of initial permeability of coal seam, and the increased amplitude and effect are obvious. After obtaining the qualitative relationship between the influencing factors and the effective drainage radius, in order to further study the quantitative relationship between these influencing factors, this paper conducts orthogonal experimental analysis on the four factors of negative pressure of drilling, drainage time, borehole diameter, and initial permeability of coal seam. 
TABLE 3: Level values of each factor.

\begin{tabular}{lcccc}
\hline Level & Hole diameter $(\mathrm{mm})$ & Extraction negative pressure $(\mathrm{MPa})$ & Initial permeability of coal seam $\left(\times 10^{-17} \mathrm{~m}^{2}\right)$ & Extraction time $(\mathrm{d})$ \\
\hline 1 & 75 & 8 & 2.4 & 20 \\
2 & 94 & 13 & 4.4 & 60 \\
3 & 113 & 18 & 6.4 & 100 \\
4 & 130 & 23 & 8.4 & 140 \\
\hline
\end{tabular}

\section{Design and Results of Orthogonal Test Scheme}

The effective gas extraction radius of the borehole is an important basis for selecting extraction methods and determining borehole layout parameters [30]. There are many factors affecting the effective gas extraction radius, but the size of the effective gas extraction radius is mainly related to the factors such as borehole diameter, extraction time, initial permeability, and extraction negative pressure. Many scholars only study the interaction between each factor and the effective drainage radius alone. In the underground field, the effective gas extraction radius is affected by the comprehensive effect of borehole diameter, permeability, extraction time, gas pressure, and other factors. In order to analyze the comprehensive effect of multiple factors, an orthogonal test was designed. Taking the effective extraction radius as the judgment index, the influence degree of each factor is obtained.

Orthogonal experimental design is a design method to arrange and analyze multifactor experiments by orthogonal table. According to the test purpose, the effective radius of extraction is determined as the test index. According to the coal seam situation in the mining area and the actual situation on-site, the level of each factor is determined. Finally, the $L_{16}\left(4^{4}\right)$ orthogonal table is selected for the test. The levels of orthogonal test factors are shown in Table 3, orthogonal test program and results are shown in Table 4. In Table 4, the test number is not the test sequence. In order to eliminate the error interference, the test arrangement can be carried out randomly.

In general, without considering the interaction between factors, the greater the change of the level of each influencing factor is, the greater the influence of this factor is. The influence degree of each factor can be obtained through range analysis. $R_{\mathrm{j}}$ represents the range of test indexes of each scheme in Column $j . k_{i j}$ represents the effective extraction radius of the scheme in Column $j$ of row $i$.

$$
R_{\mathrm{j}}=\max \left(k_{1 j}, k_{2 j}, k_{3 j}, k_{4 j}, k_{5 j}\right)-\min \left(k_{1 j}, k_{2 j}, k_{3 j}, k_{4 j}, k_{5 j}\right) .
$$

It can be seen from Table 5 that after calculating the influencing factors of effective gas extraction radius, the difference in the influence degree of each influencing factor is very small. The range analysis of the experimental results is carried out. In the experimental range, it can be obtained from the range $R$ value that the order of the influencing factors of effective gas extraction radius is drainage time$>$ initial permeability of coal seam $>$ hole diameter$>$ extraction negative pressure. However, there may be an interaction between factors in orthogonal tests, or other factors which have important influence on test results may be ignored. Therefore, in order to get more accurate and reasonable conclusions, the method of multiple linear regression analysis is proposed, and the regression coefficients of each influencing factor are analyzed.

\section{Establishment of Multiple Linear Regression Prediction Model by SPSS Software}

5.1. Establishment of Regression Model. The multiple linear regression equation is established to describe the linear relationship between the dependent variable and multiple independent variables, and the model is shown in the equation:

$$
Y=b_{0}+b_{1} x_{1}+b_{2} x_{2}+b_{3} x_{3}+b_{4} x_{4}+\cdots+b_{j} x_{j}+\varepsilon .
$$

In the formula, $\mathrm{Y}$ is the dependent variable representing the effective gas extraction radius; $x_{1}, x_{2}, x_{3}, x_{4} \ldots, x_{j}$ are $j$ controllable and measurable independent variables; $b_{0}$ is the regression constant; $b_{1}, b_{2}, \ldots, b_{j}$ are regression coefficients; $\varepsilon$ is a random variable.

In this study, the multivariate linear regression analysis method was used to analyze the orthogonal test data and establish the regression model. The multivariate linear regression equation, regression coefficient, and goodness of fit were tested to determine whether the parameters were significantly indigenous or not, and the regression diagnosis was carried out on the premise assumptions of the regression model, including residual analysis, autocorrelation analysis, and multiple collinearity analysis. Finally, in the range of sample data, according to one or several variables, the fitted mathematical expression is predicted, another variable is controlled, and the accuracy of prediction and control is tested.

5.2. Regression Model Analysis. The mathematical statistical analysis software SPSS (Statistical Package for the Social Science) was used to incorporate the data and results into SPSS to process and study the effective extraction radius data and establish a multiple linear regression model. Regression model test includes three aspects: the multiple linear regression equation, regression coefficient, goodness of fit test. Table 6 shows the model summary, and the model summary shows the approximate situation of model fitting.

(1) The goodness of fit $\left(R^{2}\right)$ refers to the fitting effect of the regression equation on the sample observation points, which is usually tested by the sample determination coefficient. $R^{2}$ is in the closed interval of 0 and 1 . The closer its value is to 1 , the better the fitting effect; the closer to 0 , the worse the fitting effect. It can be seen from Table 6 that $R^{2}=0.846$; it 
TABLE 4: Numerical simulation scheme and results of the orthogonal experiment.

\begin{tabular}{cccccc}
\hline Plan & $\begin{array}{c}\text { Hole diameter } \\
(\mathrm{mm})\end{array}$ & $\begin{array}{c}\text { Extraction negative } \\
\text { pressure }(\mathrm{MPa})\end{array}$ & $\begin{array}{c}\text { Initial permeability of coal seam } \\
\left(\times 10^{-17} \mathrm{~m}^{2}\right)\end{array}$ & $\begin{array}{c}\text { Extraction time } \\
(\mathrm{d})\end{array}$ & $\begin{array}{c}\text { The effective gas extraction radius } \\
(\mathrm{m})\end{array}$ \\
\hline 1 & 75 & 8 & 2.4 & 20 & 0.2 \\
2 & 75 & 13 & 4.4 & 60 & 0.37 \\
3 & 75 & 18 & 6.4 & 100 & 0.68 \\
4 & 75 & 23 & 8.4 & 140 & 1.58 \\
5 & 94 & 8 & 4.4 & 140 & 0.78 \\
6 & 94 & 13 & 2.4 & 100 & 0.42 \\
7 & 94 & 18 & 8.4 & 60 & 0.67 \\
8 & 94 & 23 & 6.4 & 20 & 0.32 \\
9 & 113 & 8 & 6.4 & 60 & 0.63 \\
10 & 113 & 13 & 8.4 & 20 & 0.41 \\
11 & 113 & 18 & 2.4 & 140 & 0.59 \\
12 & 113 & 23 & 4.4 & 100 & 0.71 \\
13 & 130 & 8 & 8.4 & 140 & 1.28 \\
14 & 130 & 13 & 6.4 & 20 & 1.37 \\
15 & 130 & 18 & 4.4 & 60 & 0.36 \\
16 & 130 & 23 & 2.4 & & 0.42 \\
\hline
\end{tabular}

TABLe 5: Analysis of orthogonal array test results.

\begin{tabular}{lcccc}
\hline & Hole diameter $(\mathrm{mm})$ & Extraction negative pressure $(\mathrm{MPa})$ & Initial permeability of coal seam $\left(\times 10^{-17} \mathrm{~m}^{2}\right)$ & Extraction time $(\mathrm{d})^{2}$ \\
\hline$K_{j 1}$ & 2.83 & 2.89 & 1.63 & 1.29 \\
$K_{j 2}$ & 2.19 & 2.57 & 2.22 & 2.09 \\
$K_{j 3}$ & 2.34 & 2.3 & 3 & 3.09 \\
$K_{j 4}$ & 3.43 & 3.03 & 3.94 & 4.32 \\
$k_{1}$ & 0.7075 & 0.9633 & 0.5433 & 0.43 \\
$k_{2}$ & 0.5475 & 0.8567 & 0.74 & 0.6967 \\
$k_{3}$ & 0.585 & 0.7667 & 1 & 1.03 \\
$k_{4}$ & 0.8575 & 1.01 & 1.3133 & 1.44 \\
$R$ & 0.31 & 0.2433 & 0.77 & 1.01 \\
\hline
\end{tabular}

TABle 6: Summary of multivariate analysis models ${ }^{\mathrm{b}}$.

\begin{tabular}{cccccc}
\hline Model & $\mathrm{R}$ & $R^{2}$ & $\begin{array}{c}\text { Adjusted } \\
R^{2}\end{array}$ & $\begin{array}{c}\text { Standard estimation } \\
\text { error }\end{array}$ & $\mathrm{D}-\mathrm{W}$ \\
\hline 1 & $0.920^{\mathrm{a}}$ & 0.846 & 0.790 & 0.18461 & 1.632 \\
\hline
\end{tabular}

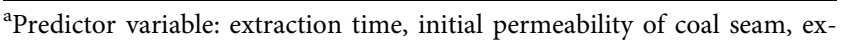
traction negative pressure, and hole diameter. ${ }^{b}$ Dependent variable: effective gas extraction radius.

indicates that the established multiple regression model can explain $82.2 \%$ of the predicted variables (effective extraction radius).

(2) Autocorrelation analysis: when constructing the regression equation, the phenomenon of autocorrelation of random error terms sometimes occurs, which will lead to inaccurate prediction and estimation of the regression equation and a decrease in prediction accuracy. This paper uses the D-W test method to test the autocorrelation of the random error term. According to the D. W judgment criterion, 1.632 is in the interval of $0-5$, so it is impossible to judge whether there is autocorrelation between random error terms.

(3) Analysis of variance: Table 7 above is the test result of the model significance $\mathrm{F}$ between the established drainage aperture, drainage negative pressure, initial coal permeability, drainage time, and effective drainage radius. $F=15.102$, the significance value is 0.000192 , which is less than 0.005 , indicating that the regression model between drainage aperture, Extraction negative pressure, Initial permeability of coal seam, Extraction time, and effective drainage radius is significant, that is, drainage aperture, Extraction negative pressure, initial permeability of coal seam, and Extraction time are the main factors that affect the effective gas extraction radius.

(4) Estimation of the regression coefficient: the estimation of the regression coefficient of the model is shown in Table 8, so the multiple linear regression equation is as follows:

$Y=-0.621+0.003 x_{1}+0.001 x_{2}-0.096 x_{3}-0.006 x_{4}$

$Y$ is the dependent variable representing the effective gas extraction radius; $x_{1}$ represents the effect of borehole diameter on effective drainage radius; $x_{2}$ represents the influence of negative pressure on effective extraction radius; $x_{3}$ represents the effect of initial permeability on effective drainage radius; $x_{4}$ represents the effect of extraction time on effective extraction radius.

(5) Regression coefficient and explicitness test, and $t$-test is the explicitness test of a single independent variable. The significance column records the 
TABLE 7: Multivariate analysis model significance test table ${ }^{\mathrm{b}}$.

\begin{tabular}{|c|c|c|c|c|c|}
\hline Model & Sum of squares & Degree of freedom & Mean square & $\mathrm{F}$ & Significance \\
\hline Return & 2.059 & 4 & 0.515 & 15.102 & $0.000192 b$ \\
\hline Residual & 0.375 & 11 & 0.034 & & \\
\hline Total & 2.434 & 15 & & & \\
\hline
\end{tabular}

${ }^{a}$ Dependent variable: effective gas extraction radius. ${ }^{b}$ Predictor variable: extraction time, initial permeability of coal seam, extraction negative pressure, and hole diameter.

TABLE 8: Multiple regression coefficient table.

\begin{tabular}{|c|c|c|c|c|c|c|c|}
\hline \multirow[t]{2}{*}{ Model } & \multicolumn{2}{|c|}{$\begin{array}{c}\text { Nonstandardized } \\
\text { coefficient }\end{array}$} & \multirow[t]{2}{*}{ Standardization factor beta } & \multirow[t]{2}{*}{$t$} & \multirow[t]{2}{*}{ Significance } & \multirow[t]{2}{*}{ Tolerance } & \multirow[t]{2}{*}{ VIF } \\
\hline & $\mathrm{B}$ & Standard error & & & & & \\
\hline Constant & -0.621 & 0.302 & & -2.059 & 0.064 & & \\
\hline Hole diameter & 0.003 & 0.002 & 0.133 & 1.123 & 0.286 & 1.000 & 1.000 \\
\hline Extraction negative pressure & 0.001 & 0.008 & 0.011 & 0.091 & 0.929 & 1.000 & 1.000 \\
\hline Initial permeability of coal seam & 0.096 & 0.021 & 0.553 & 4.669 & 0.001 & 1.000 & 1.000 \\
\hline Extraction time & 0.006 & 0.001 & 0.723 & 6.111 & 0.000 & 1.000 & 1.000 \\
\hline
\end{tabular}

significance values corresponding to each influencing factor of the effective extraction radius. Here, the significant value of initial permeability and extraction time is less than 0.05 , and the corresponding significant value of other influencing factors is greater than 0.05 . Therefore, it can be determined that the extraction time has the greatest impact on the effective extraction radius, followed by the initial permeability.

(6) Variance expansion factor (VIF): this value is the reciprocal of tolerance. The larger the value of VIF, the more serious the collinearity problem. When VIF $>10$, there is a stronger collinearity problem. The VIF from the drainage aperture, drainage negative pressure, initial permeability, and drainage time are all 1.000 , so there is no collinearity between the model independent variables.

(7) Residual error analysis: the purpose of the residual analysis is to test and ensure the quality of the test data and diagnose the regression effect. In regression analysis, there will be a type of test values that are outliers, which are far away from other values and manifest as large residuals, which affect the effect of regression equation fitting. It can be seen from Table 9 that the standard residuals are $<3$, and the standard predicted values are $<3$, indicating that the observed data are not abnormal values and will not affect the fitting effect of the regression equation.

(8) Scatter plot of regression residuals: the scatter plot of the regression standardized residual is shown in Figure 9. It can be seen from Figure 9 that the fitting effect of the multiple linear regression equation is good.

Therefore, the conclusion drawn through the analysis of the multiple linear regression model is that there are 4 main factors affecting the effective gas extraction radius of the end, which are the extraction negative pressure, the hole diameter, initial permeability of coal seam, and the extraction time. Because the absolute value of the standard regression coefficient reflects the size of the effective extraction radius, the greater the absolute value, the greater the impact on performance. It can be seen from the above table that the degree of influence from large to small is the Initial permeability of coal seam, extraction time, hole diameter, and extraction negative pressure. It can be considered that the main influencing factors of the effective drainage radius are the initial permeability of coal seam and extraction time. Based on the above analysis, the increase of hole diameter and extraction negative pressure has no obvious influence on the effective radius. In practical work, the size of borehole diameter and extraction negative pressure can be reasonably selected according to the economic and engineering conditions. With the increase of mining depth, the gas content and gas pressure gradually increase, and the permeability of the coal seam gradually decreases. In the same time, the effective radius of gas extraction is getting smaller and smaller, and the extraction standard is becoming more and more difficult. It is necessary to take pressure relief and permeability enhancement measures, such as mining protective layer, hydraulic cutting, and hydraulic fracturing, to improve the permeability of coal seam so as to improve the extraction effect, reduce the possibility of disasters and ensure safe production.

\section{Field Measurement Investigation of Effective Extraction Radius}

6.1. Field Test Plan. Juji Coal Mine is a coal and gas outburst mine. At present, the mining coal seam is coal seam No.2, which is located in the middle of the Shanxi Formation. The thickness of the coal seam is $0.80 \sim 8.86 \mathrm{~m}$, with an average of $2.60 \mathrm{~m}$. The dip angle of the coal seam is near horizontal and the structure is simple. According to the mining conditions of the coal seam, the single strike longwall backward comprehensive mechanized coal mining method is adopted. All the caving method is used to manage the roof and the whole mining height is once mined. The direct top is mostly 
TABle 9: Residual statistics.

\begin{tabular}{lccccc}
\hline & Minimum & Maximum & Average & Standard deviation & Number of cases \\
\hline Predictive value & -0.0692 & 1.2770 & 0.6744 & 0.37048 & 16 \\
Residual & -0.20068 & 0.3030 & 0.00 & 0.15809 & 16 \\
Standard forecast & -2.007 & 1.627 & 0.00 & 1.000 & 16 \\
Standard residual & -1.087 & 1.641 & 0.00 & 0.856 & 16 \\
\hline
\end{tabular}

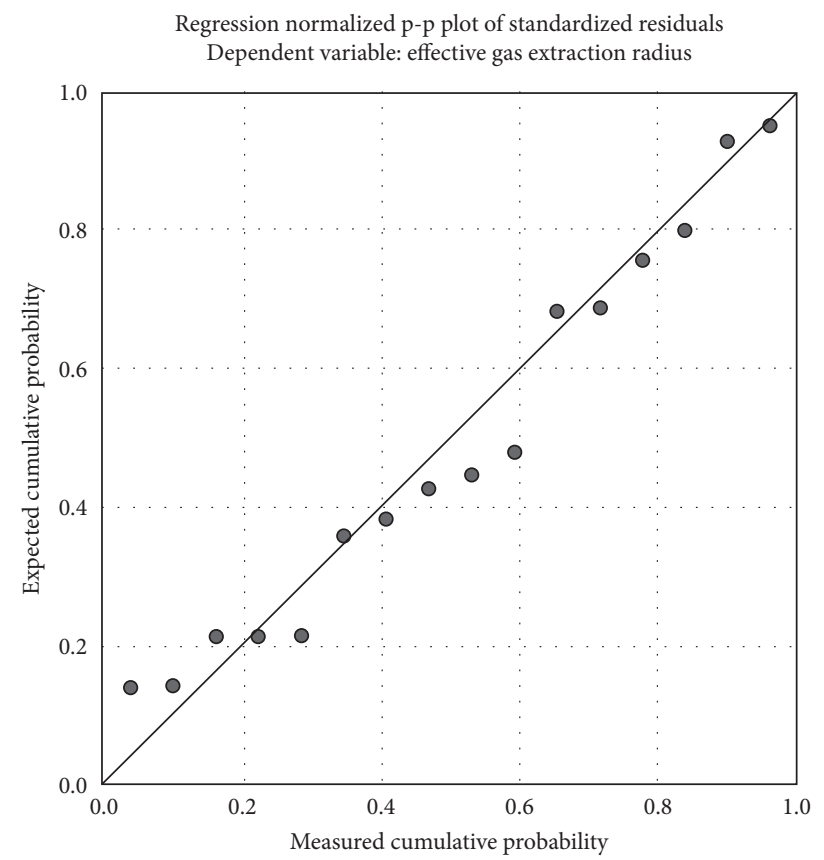

FIGURE 9: Scatter plot of regression standardized residuals.

mudstone or sandy mudstone and siltstone, and various sizes of sandstone can be seen locally. Coal seam floor is mostly mudstone or sandy mudstone, siltstone.

The test site was selected in 2616 Bottom Roadway, and the flow test borehole is $20 \mathrm{~m}$ away from the drainage borehole. Then, according to the geological conditions of the test site, parameter design is carried out on the drainage borehole of the bottom drainage lane [31-33]. The specific parameters are shown in Table 10 below. After the drilling is completed, the diameter of the extraction hole is connected to the extraction pipeline for extraction, the extraction negative pressure is $18 \mathrm{kPa}$, a separate flowmeter is set, and the concentration of the extraction gas is tested.

6.2. Measured Results of Effective Extraction Radius. Through the recording and processing of on-site drainage data (Figure 10 shows the on-site construction), the borehole measurement points of the 2616 Bottom Roadway are obtained, and the gas drainage scalar changes with time are shown in Figure 11.

6.3. Determination of Effective Drainage Radius by Flow Method. Substituting the gas flow attenuation index equation $q_{\mathrm{ct}}=q_{\mathrm{c} 0} \mathrm{e}(-\beta \mathrm{t})$ into formulas (8)-(10) for the gas flow rate attenuation index equation of a single borehole through a cross-layer borehole, the extraction rate is used as an index to determine the effective gas drainage radius.

The gas predrainage rate is the main indicator to measure the effect of predraining coal seam gas by drilling holes. According to the original gas content $\mathrm{W}$ of the coal seam measured, when the influence radius of the drilling hole is $r$ during the extraction time $t$, the gas reserves $Q$ within the control range of the drilling hole can be calculated, and then calculate the gas predrainage rate in time $t$, which is the ratio of gas drainage quantity Qct to $Q$ :

$$
\begin{aligned}
& Q=2 r \cdot h \cdot L \cdot \gamma \cdot W \\
& \eta=\frac{Q_{c t}}{Q}=\frac{1440 q_{c 0}\left(1-e^{-\beta t}\right)}{(2 r \cdot h \cdot L \cdot \gamma \cdot W)} .
\end{aligned}
$$

In the formula, $Q_{c t}$ is the total amount of gas drainage from the borehole at any time $t, \mathrm{~m}^{3}$, Qis the gas reserves within the control range of the borehole, $\mathrm{m}^{3} ; \eta$ is the gas predrainage rate within time $t, \% ; r$ is the drainage radius, $m$; $h$ is the thickness of the coal seam, $m$; Lis the length of the drainage hole, $m ; \gamma$ is the density of the coal, $\mathrm{t} / \mathrm{m}^{3} ; W$ is the original gas content of the coal seam, $\mathrm{m}^{3} / \mathrm{t}$.

$$
r \leq \frac{1440 q_{c 0}\left(1-e^{-\beta t}\right)}{(2 \eta \cdot h \cdot L \cdot \gamma \cdot W \cdot \beta)}
$$


TABle 10: Parameters of extraction borehole.

\begin{tabular}{lcccccc}
\hline $\begin{array}{l}\text { Design } \\
\text { angle }\left({ }^{\circ}\right)\end{array}$ & $\begin{array}{c}\text { Design } \\
\text { inclination }\left({ }^{\circ}\right)\end{array}$ & $\begin{array}{c}\text { Drill hole see coal } \\
\text { hole depth }(\mathrm{m})\end{array}$ & $\begin{array}{c}\text { Drilling depth } \\
(\mathrm{m})\end{array}$ & $\begin{array}{c}\text { Hole diameter } \\
(\mathrm{mm})\end{array}$ & $\begin{array}{c}\text { The construction of } \\
\text { the place }\end{array}$ & Height of opening (m) \\
\hline-90.0 & 90.0 & 14.5 & $\begin{array}{c}\text { Not less than } \\
1 \mathrm{~m}\end{array}$ & 94 & 2616 bottom roadway & $\begin{array}{c}\text { The center line is } 0.5 \mathrm{~m} \\
\text { to the right }\end{array}$ \\
\hline
\end{tabular}

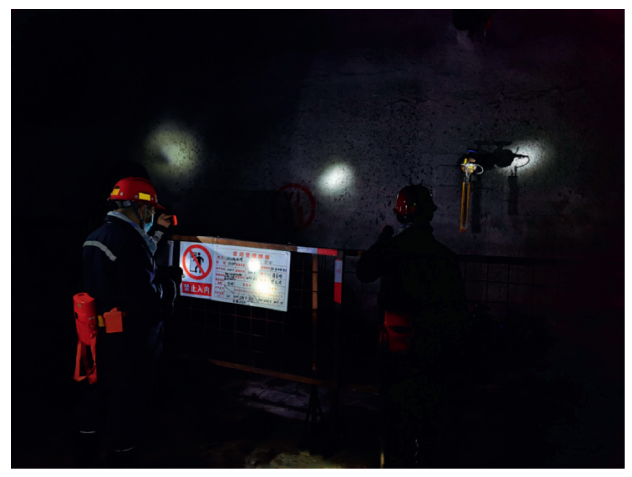

(a)

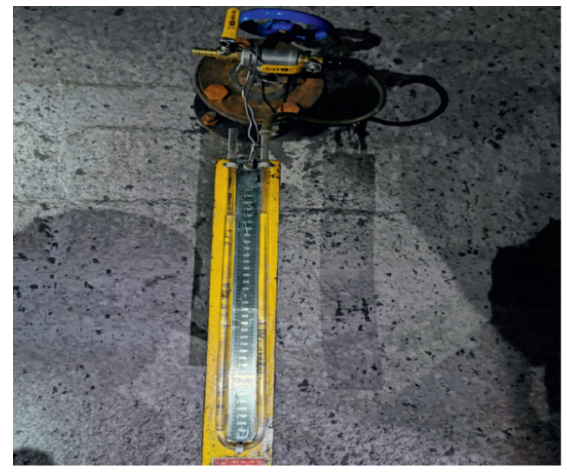

(b)

FIgURe 10: Site construction.

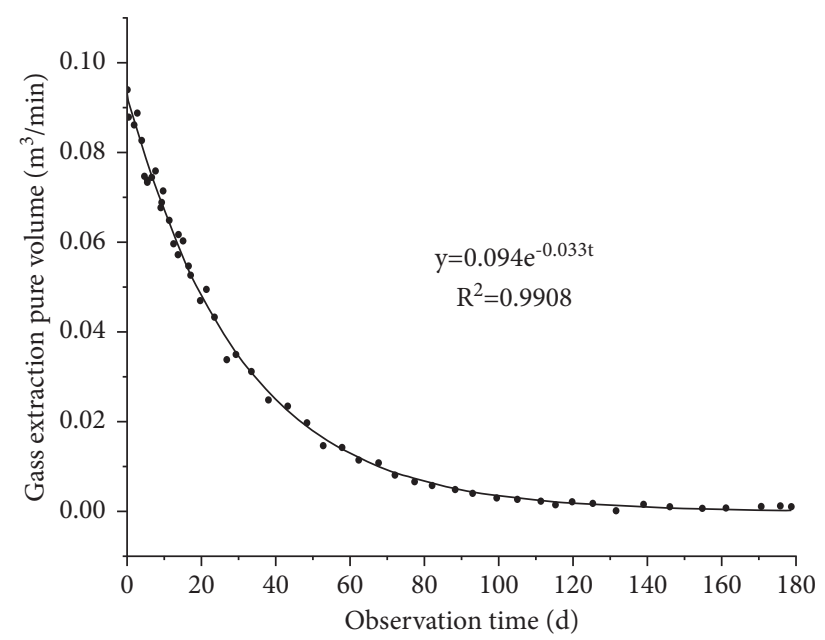

FIGURE 11: Variation law of drilling extraction pure quantity with extraction time in 26 mining areas of Juji Coal Mine.

According to the above method: under the premise of the drainage rate of $30 \%$, the effective drainage radius is $0.41 \mathrm{~m}$ when the drilling time of the 26 mining area is 30 days; when the drilling time of the 26 mining area is 60 days, the effective drainage radius is $0.65 \mathrm{~m}$; when the drainage time is 120 days, the effective drainage radius is $1.29 \mathrm{~m}$; when the drainage time is 180 days, the effective drainage radius is $1.43 \mathrm{~m}$. The measured value is slightly different from the simulated value above, which is in line with the actual situation. It verifies the correctness of the gas-containing coal stress-seepage coupling model and the feasibility of using COMSOL software to simulate and calculate the effective drainage radius of the coal seam.

\section{Conclusions}

(1) Based on the gas flow theory and elastic mechanics, considering the influence of the damage and deformation of coal skeleton and the change of coal permeability on gas flow, and based on the actual data and data of Juji Coal Mine, the gas-solid coupling model of stress-damage-seepage of coal rock containing gas is used. According to this model, the COMSOL Multiphysics numerical simulation software is secondarily developed to explore various influencing factors.

(2) The simulation using COMSOL Multiphysics clearly shows the influence of the diameter of the drainage 
borehole, the negative pressure of the drainage, the initial gas permeability of the coal seam and the extraction time on the effective extraction radius in a qualitative form, and the initial coal permeability and drainage. The extraction time has a significant effect on the effective gas extraction radius, and the negative pressure and the extraction diameter have a limited effect on the effective extraction radius. Through field measurement, it can be concluded that the numerical simulation method based on the gassolid coupling model is basically consistent with the measured results of the pressure method, which shows the accuracy of the numerical simulation.

(3) The SPSS statistical software was used to perform multiple linear regression analysis on various influencing factors, and the multiple linear regression equation of the effective drainage radius was obtained, and the regression model that affected the effective drainage radius of the borehole was established. Through F-test, $t$-test, and regression diagnosis on the regression model, it is obtained that there is no collinearity among the initial coal seam permeability, drainage time, negative pressure of drainage, and borehole diameter, and it has significant effects on the regression equation and regression coefficients as a whole. The effect of multiple linear regression equations is good, and the multiple linear regression analysis models can be used to relatively accurately reflect the impact of influencing factors on the effective drainage radius. And it is concluded that in order to improve the effect of gas drainage, it is necessary to implement various antipermeability measures such as hydraulic fracturing, hydraulic slitting, etc., from the two perspectives of increasing coal seam permeability and extending gas drainage time as much as possible, easily achieving significant results.

\section{Data Availability}

The data used to support the findings of this study are available from the corresponding author upon request.

\section{Conflicts of Interest}

The authors declare that they have no conflicts of interest.

\section{Acknowledgments}

The authors acknowledge the financial support from the National Natural Science Foundation of China Youth Fund (no. 51904082) and the National Natural Science Foundation of China Regional Fund (nos. 52064005, 52164002, and 52164005) and the funding from Guizhou Science and Technology Plan Project (Qianke Science Foundation [2020] $1 Y 214$ and Qianke Science Support [2021] General 399).

\section{References}

[1] D.-Z. Kong, Z.-B. Cheng, and S.-S. Zheng, "Study on the failure mechanism and stability control measures in a largecutting-height coal mining face with a deep-buried seam," Bulletin of Engineering Geology and the Environment, vol. 78, no. 8, pp. 6143-6157, 2019.

[2] D. Z. Kong, S. J. Pu, Z. H. Cheng, and G. Wu, "Coordinated deformation mechanism of the top coal and filling body of gob-side entry retaining in a fully mechanized caving face," International Journal of Geomechanics, vol. 21, no. 4, 2021.

[3] B. Liang, X. P. Yuan and W. J. Sun, Seepage coupling model of in-seam gas extraction and its applications," Journal of China University of Mining \& Technology, vol. 43, no. 2, pp. 208-213, 2014.

[4] Z. M. Zhao, W. Dong, G. Y. Wei, and T. W. Shi, "Numerical simulation study and application of hectometre borehole gas flowrate," Journal of Mining \& Safety Engineering, vol. 35, no. 2, pp. 436-441, 2018.

[5] J. J. Liu, G. N. Jia, D. Wang, and Q. Ma, "Study on optimization of gas drainage parameters with borehole drilled along seam based on coupling of multi physical field," Coal Science and Technology, vol. 46, no. 7, pp. 115-119+156, 2018.

[6] F. C. Hao, Y. W. Liu, W. C. Long, and W. Q. Zuo, "Effective gas extraction radius of different burial depths under creepseepage coupling," Journal of China Coal Society, vol. 42, no. 10 , pp. 2616-2622, 2017.

[7] G. Z. Yin, M. H. Li, S. Z. Li, W. P. Li, J. W. Yao, and Q. G. Zhang, "3D numerical simulation of gas drainage from boreholes based on solid-gas coupling model of coal containing gas," Journal of China Coal Society, vol. 38, no. 4, pp. 535-541, 2013.

[8] D. K. Wang, M. Peng, Q. C. Fu, H. J. Qin, and Y. L. Xia, "Evolution and numerical simulation of coal permeability during gas drainage in coal seams," Chinese Journal of Rock Mechanics and Engineering, vol. 35, no. 4, pp. 704-712, 2016.

[9] Z. Liu, Y. Cheng, J. Jiang, W. Li, and K. Jin, "Interactions between coal seam gas drainage boreholes and the impact of such on borehole patterns," Journal of Natural Gas Science and Engineering, vol. 38, pp. 597-607, 2017.

[10] Q. Liu, Y. Cheng, H. Zhou, P. Guo, and F. An, "Mathematical model of coupled gas flow and coal deformation with gas diffusion and Klinkenberg effects," Rock Mechanics and Rock Engineering, vol. 48, no. 3, pp. 1163-1180, 2015.

[11] D. Z. Kong, Y. Xiong, Z. B. Cheng, and N. Wang, "Stability analysis of coal face based on coal face-support-roof system in steeply inclined coal seam," Geomechanics and Engineering, vol. 25, no. 3, pp. 233-243, 2021.

[12] H. W. Wang, "Determination of effective radius and influence of gas content in bedding drilling gas drainage," Coal Science and Technology, vol. 46, no. S1, pp. 131-134, 2018.

[13] H. M. Cheng, Y. M. Li, and C. L. Dong, "Research into the infcuencing factors and measuring methods of efective radius for gas drainage using hole drilled along seam," China Mining Magazine, vol. 26, no. 5, pp. 127-131, 2017.

[14] N. P. Yao, J. Zhang, X. Jin, and H. Hanjing, "Status and development of directional drilling technology in coal mine," Procedia Engineering, vol. 73, pp. 289-298, 2014.

[15] L. Zhang, H. Zhang, and H. Guo, "A case study of gas drainage to low permeability coal seam," International Journal of Mining Science and Technology, vol. 27, no. 4, pp. 687-692, 2017.

[16] H. Guo, C. Todhunter, Q. D. Qu, and Z. Y. Qin, "Longwall horizontal gas drainage through goaf pressure control," 
International Journal of Coal Geology, vol. 150, pp. 276-286, 2015.

[17] Y. Lu, W. X. Gu, G. Wang, H. Li, S. L. Shi, and H. Y. Niu, "Numerical assessment of the influences of the coal spontaneous combustion on gas drainage methods optimization and its application," Combustion Science and Technology, vol. 193, no. 12 , pp. $2158-2174,2021$.

[18] S. Q. Lu, Y. P. Cheng, J. M. Ma, and Y. B. Zhang, "Application of in-seam directional drilling technology for gas drainage with benefits to gas outburst control and greenhouse gas reductions in Daning coal mine, China," Natural Hazards, vol. 73, no. 3, pp. 1419-1437, 2014.

[19] J. Liu, Y. Xue, Q. Zhang, H. Wang, and S. Wang, "Coupled thermo-hydro-mechanical modelling for geothermal doublet system with 3D fractal fracture," Applied Thermal Engineering, vol. 200, Article ID 117716, 2022.

[20] L. Zhu, F. Dang, Y. Xue, K. Jiao, and W. Ding, "Multivariate analysis of effects of microencapsulated phase change materials on mechanical behaviors in light-weight aggregate concrete," Journal of Building Engineering, vol. 42, Article ID 102783, 2021.

[21] G. H. Chen, Z. Y. Wei, and D. F. Liang, "Practice of gas extraction by high directional long borehole in close distance coal seam group," Mining Safety \& Environmental Protection, vol. 46, no. 5, pp. 66-69, 2019.

[22] T. T. Li, B. Wu, and B. W. Lei, "Study on the optimization of a gas drainage borehole drainage horizon based on the evolution characteristics of mining fracture," Energies, vol. 12, no. 23, 2019.

[23] X. B. Zhang, S. S. Shen, X. J. Feng, and Y. Ming, "Influence of deformation and instability of borehole on gas extraction in deep mining soft coal seam," Advances in Civil Engineering, vol. 2021, Article ID 6689277, 11 pages, 2021.

[24] Y. Q. Shang, G. Y. Wu, Q. Z. Liu, D. Z. Kong, and Q. Li, "The drainage horizon determination of high directional long borehole and gas control effect analysis," Advances in Civil Engineering, vol. 2021, Article ID 3370170, 11 pages, 2021.

[25] Y. Xiong, D. Z. Kong, and Z. B. Cheng, "The comprehensive identification of roof risk in a fully mechanized working face using the cloud model," Mathematics, vol. 9, no. 17, p. 2072, 2021.

[26] S. Tao, S. D. Chen, and Z. J. Pan, "Current status, challenges, and policy suggestions for coalbed methane industry development in China: a review," Energy Science \& Engineering, vol. 7, pp. 1-16, 2019.

[27] S. Tao, Z. J. Pan, S. L. Tang, and S. D. Chen, "Current status and geological conditions for the applicability of CBM drilling technologies in China: a review," International Journal of Coal Geology, vol. 202, pp. 95-108, 2019.

[28] G. Y. Si and B. Belle, "Performance analysis of vertical goaf gas drainage holes using gas indicators in Australian coal mines," International Journal of Coal Geology, vol. 216, 2014.

[29] J. F. Lou, F. Q. Gao, J. H. Yang, Y. F. Ren, J. H. Li, and X. Q. Wang, "Characteristics of evolution of mining-induced stress field in the longwall panel: insights from physical modeling," International Journal of Coal Science \& Technology, vol. 8, no. 5, 2021.

[30] Z. Song, T. Frühwirt, and H. Konietzky, "Inhomogeneous mechanical behaviour of concrete subjected to monotonic and cyclic loading," International Journal of Fatigue, vol. 132, Article ID 105383, 2020.

[31] Y. L. Wu, S. Tao, W. G. Tian, H. Chen, and S. D. Chen, "Advantageous seepage channel in coal seam and its effects on the distribution of high-yield areas in the fanzhuang CBM block, southern qinshui basin, China," Natrual Resources Research, vol. 30, no. 3, pp. 2361-2376, 2021.

[32] Z. Song, Y. Wang, H. Konietzky, and X. Cai, "Mechanical behavior of marble exposed to freeze-thaw-fatigue loading," International Journal of Rock Mechanics and Mining Sciences, vol. 138, Article ID 104648, 2021.

[33] X. Y. Men, S. Tao, Z. X. Liu, W. G. Tian, and S. D. Chen, "Experimental study on gas mass transfer process in a heterogeneous coal reservoir," Fuel Processing Technology, vol. 216, Article ID 106779, 2021. 